\title{
DEFENSAS FISCALES EN CONTRA DE MULTAS POR INFRACCIONES FISCALES QUE PUEDEN TRAMITAR LOS ESTUDIANTES DE DERECHO
}

\section{Por Fausto León Cervantes ${ }^{20}$}

SUMARIO: Introducción. I. Recurso de Revocación II. Solicitud de condonación de multa. III. Reconsideración o Revisión Administrativa IV. Conclusiones

\section{RESUMEN}

En este documento se aborda de manera didáctica y amena el tema de los recursos administrativos que como medios de defensa pueden seguir tanto el contador público como el estudiante (ambos no profesionales del derecho) al pretender que la autoridad administrativa hacendaria deje sin efecto las multas por infracciones a las leyes federales fiscales. Básicamente el recurso de revocación, la solicitud de condonación de multa y la reconsideración administrativa regulados por el Código Fiscal de la Federación, incluyendo las Tesis de Jurisprudencia de la Suprema Corte de Justicia de la Nación aplicables a cada caso.

Palabras clave: Medios de defensa, infracciones fiscales

\section{ABSTRACT}

This paper addresses the subject of administrative resources, in an enjoyable and educational way, that may be followed by the public accountant or student (without any of them being legal professionals) in claims against the tax authority for the revocation of its decisions related to fines for the violation of federal tax laws.

Basically, the appeal of revocation, the request for remission of penalty and the administrative reconsideration, all of them regulated by the Fiscal Code of the Federation, besides the thesis of jurisprudence of the Supreme Court of Justice applicable to each case

Key Words: Legal appeals, fines, federal tax laws

\section{Introducción}

${ }^{20}$ Profesor Indeterminado de las Asignaturas de Seminario de Derecho Procesal Fiscal, Seminario de Derecho Fiscal del Departamento de Derecho de la Universidad de Sonora URC 
Todo ciudadano tiene derecho no solo a conocer cuáles son los medios de defensa que le otorgan las leyes, sino a conocer aquellos que puede por sí mismo utilizar, en el supuesto de que alguna autoridad administrativa pretenda afectar su esfera jurídica personal o patrimonial, para ello, cabe recordar en palabras del maestro Emilio Margain Manautou, " que el recurso administrativo es todo medio de defensa al alcance de los particulares para impugnar ante la administración pública los actos y resoluciones por ella dictados en perjuicio de los propios particulares, por violación al ordenamiento aplicado o a falta de aplicación de la disposición debida." ${ }^{21}$ Al efecto conviene preguntarnos ¿cuáles son en materia administrativa fiscal esos recursos?

Las defensas más accesibles que puede tramitar el contador público o estudiantes de derecho 0 de licenciaturas afines ${ }^{22}$, son el recurso de revocación, la solicitud de condonación de multa y la reconsideración administrativa regulados por el Código Fiscal de la Federación en el tercer párrafo del Artículo 36 y los Artículos 74 y 117 de ese ordenamiento.

\section{Recurso de revocación}

Primeramente nos referiremos al recurso de revocación, que tiene requisitos de forma para su trámite y resolución como son:

${ }^{21}$ Margain Manautou, Emilio "El Recurso Administrativo en México", Editorial Porrúa 2010, p.18

${ }^{22}$ interesados en dar la oportunidad a la autoridad administrativa -- emisora de la resolución que le causa perjuicio-- de examinar su actuación, a la luz del cristal de la legalidad de las disposiciones aplicadas en la observancia de su esfera de competencia y, en consecuencia de esta revisión, confirmar, revocar o modificar sus resoluciones fijando con claridad su actitud frente al particular. Evitando con ello, que el particular promoverte acuda a la siguiente instancia en juicio de nulidad ante el Tribunal Federal de Justicia Fiscal y Administrativa. 
1.- Anexar copia certificada de la escritura pública en donde se le otorga poder para pleitos y cobranzas al que suscribe.

a).- En este caso se debe cerciorar que no sea un poder mancomunado con otra firma y que el nombre sea el que aparezca en la escritura.

b).- Y anexar copia certificada de la credencial de elector.

c).- Dirigirlo a la administración local jurídica del Servicio de Administración Tributaria.

d).- Indicar el Registro Federal de Contribuyentes., domicilio fiscal y domicilio para oír notificaciones.

e).- Suscribir o firmar el recurso con tinta azul y llevar dos copias con anexos a la oficialía de partes de la administración local jurídica. Sí no se encuentra el apoderado o representante se tiene que solicitar su permiso para hacer la firma lo más parecida posible.

f).- Se tienen 45 días hábiles para presentarlo y empieza a contar un día después de que surta efectos la notificación del oficio de multa. Ejemplo: Se notifica un lunes, surte efectos el martes y empieza a contar el miércoles o sí se notifica un viernes, el lunes surte efectos y el martes empieza a contar el término.

2.- Copias simples o en su caso certificadas de los oficios de autoridad que sancionan a la empresa. En un sólo recurso pueden impugnarse varias multas sí se trata del mismo contribuyente. Hacer relación de documentos anexos al final del Escrito. 
Sí se impugna una firma del oficio que no es autógrafa u original se tiene que anexar el documento original para su cotejo. En este caso, existe una Jurisprudencia en la que se apoya la autoridad fiscal en la cual, cualquier objeción a una firma se tiene que probar con la prueba caligráfica resultando más onerosa la defensa que la multa misma. No obstante, también existen criterios relevantes en los que se advierte que por tratarse de un hecho notorio, éste no está sujeto a prueba, como lo es una copia simple o al carbón. Pero este alegato tiene que exponerse en el Juicio de Nulidad ante el Tribunal Federal de Justicia Fiscal y Administrativa.

Actualmente todas las firmas del Servicio de Administración Tributaria son originales, no así las del Gobierno del Estado que en ocasiones entregan la copia al carbón en vez del original al contribuyente.

3.- La expresión de agravios (la parte más importante del recurso) puede hacerse parafraseando una Tesis o Jurisprudencia del Tribunal Federal de Justicia Fiscal y Administrativa o de la Suprema Corte de Justicia de la Nación en donde se explica cuál es la omisión en que incurrió la autoridad fiscal y además, transcribirla en el recurso.

Lo más recomendable es usar un lenguaje ordinario que a la primera leída se comprenda la idea esencial. No usar palabras o frases difíciles de entender pues ni la Suprema Corte de Justicia de la Nación las utiliza para dictar sus criterios.

4.- Cuando después de presentado el recurso de revocación se percataran de la existencia de un agravio que no se expuso, se puede enderezar la defensa completando el recurso sí todavía no han vencido los 45 días, o una vez resuelto, exponerlo en la demanda de nulidad conforme al último párrafo del Artículo $1^{\circ}$ de la Ley Federal del Procedimiento Contencioso Administrativo: 
"Asimismo, cuando la resolución a un recurso administrativo declare por no interpuesto o lo deseche por improcedente, siempre que la Sala Regional competente determine la procedencia del mismo, el juicio contencioso administrativo procederá en contra de la resolución objeto del recurso, pudiendo en todo caso hacer valer conceptos de impugnación no planteados en el recurso."

5.- En el Artículo 129 del Código Fiscal de la Federación se regula la impugnación de notificaciones y cuando se desconozca algún documento que tenga relación con las obligaciones fiscales del contribuyente, se tendrá que utilizar la frase "se niega en forma lisa y llana" y la carga de la prueba le corresponderá a la autoridad y la exhibición del mismo en copia certificada. Debiendo ampliar el recurso de revocación dentro de los 20 días después de notificada esa copia y sus actas de notificación, impugnando tanto la notificación como esa copia.

\footnotetext{
"FIRMA AUTÓGRAFA NO SE ACREDITA QUE UN DOCUMENTO LA CONTENGA, CON LA COPIA FOTOSTÁTICA CERTIFICADA DEL MISMO.- Con una copia fotostática certificada de un documento, no se puede acreditar que éste haya sido firmado autógrafamente, si no se certifica a su vez que el original que se tuvo a la vista contiene firma autógrafa, pues dada la naturaleza de las fotocopias, la firma en ellas reproducida aparece para los no expertos como facsimilar"

Octava Época, Instancia: Tribunales Colegiados de Circuito. Fuente: Semanario Judicial de la Federación. VII, Junio de 1991. Página: 277. Tesis Aislada. Materia Administrativa.
}

6.- En la última acta parcial de una visita domiciliaria o en el oficio de observaciones de una revisión de gabinete no hacer uso de la inconformidad de los 20 días para presentar pruebas o alegar lo que a su derecho convenga porque esas defensas no tendrán efecto alguno en la resolución fiscal (corregirá los errores la autoridad) y sí en un medio de defensa. 
7.- Tener en cuenta también la Ley Federal de Derechos del Contribuyente publicada en el Diario Oficial de la Federación el 23 de Junio del 2005 en el inicio de las Facultades de Comprobación:

"Artículo $\mathbf{1}^{\circ}$.- La presente Ley tiene por objeto regular los derechos y garantías básicos de los contribuyentes en sus relaciones con las autoridades fiscales. En defecto de lo dispuesto en el presente ordenamiento, se aplicarán las leyes fiscales respectivas y el Código Fiscal de la Federación.

Los derechos y garantías consagradas en la presente Ley en beneficio de los contribuyentes, les serán igualmente aplicables a los responsables solidarios."

Es decir, que sólo en defecto de esta Ley se aplicarán todos los demás ordenamientos Fiscales y el Código Fiscal de la Federación o las Autoridades Fiscales no pueden restringir o limitar la aplicación de la Ley Federal de los Derechos del Contribuyente.

"Artículo 20.- Son derechos generales de los contribuyentes los siguientes:

XIII.- Derecho a corregir su situación fiscal con motivo del ejercicio de las facultades de comprobación que lleven a cabo las autoridades fiscales.

Artículo 12.- Los contribuyentes tendrán derecho a ser informados, al inicio de cualquier actuación de la autoridad fiscal, para comprobar el cumplimiento de las obligaciones fiscales, de sus derechos y obligaciones en el curso de tales actuaciones.

Artículo 13.- Cuando las autoridades fiscales ejerzan sus facultades para comprobar el cumplimiento de las obligaciones fiscales previstas en las fracciones II y III del artículo 42 del Código Fiscal de la Federación, deberán informar al contribuyente con el primer acto que implique el inicio de esas facultades, el derecho que tiene para corregir su situación fiscal y los beneficios de ejercer el derecho mencionado. 
Artículo 20.- Las autoridades fiscales podrán revisar nuevamente los mismos hechos, contribuciones y períodos, por los que se tuvo al contribuyente por corregido de su situación fiscal, o se le determinaron contribuciones omitidas, sin que de dicha revisión pueda derivar crédito fiscal alguno a cargo del contribuyente."

\section{Solicitud de condonación de multa}

8.- Para el trámite de la solicitud de condonación de multa conforme al Artículo 74 del Código Fiscal de la Federación se requiere que el crédito fiscal quede firme: Que no se haya presentado defensa dejando pasar el término de 45 días o se haya resuelto la defensa en forma desfavorable. Es accesible porque no requieren mayores requisitos más que exponer hechos, no puntos de derecho que le perjudican, es decir, que se tienen pérdidas, no se han registrado ingresos, gastos fijos altos, cierre de la empresa, reducción de nómina, etc., pudiéndose probar con las declaraciones mensuales o anuales, así como copia de pagos al Instituto Mexicano del Seguro Social o bajas.

\section{III.RECONSIDERACIÓN O REVISIÓN ADMINISTRATIVA}

9.- La reconsideración administrativa también es otra opción para revocar o modificar las resoluciones fiscales en contra de los contribuyentes:

Este recurso o revisión se encuentra en el tercer párrafo del Artículo 36 del Código Fiscal de la Federación y es recomendable su utilización cuando el contribuyente no se haya defendido en tiempo y el crédito fiscal derivado de una resolución se encuentre firme, siempre y cuando se estudie previamente la diligencia de notificación pues en ese caso todavía puede impugnarse con el recurso de revocación o con una demanda de nulidad.

En este punto se recomienda intentar esta defensa ya que no tiene mayores requisitos que los de un recurso de revocación y no tiene término 
alguno para presentarla. $\mathrm{Y}$ es muy común que los contribuyentes olviden defenderse o se pague el adeudo siendo injusto el cobro que se hace por el Servicio de Administración Tributaria.

Lo anterior no significa consentimiento alguno pues esta reconsideración administrativa abre la posibilidad de impugnar esos créditos que se creía que no tenían más remedio que cubrirse.

"Artículo 36.- Las resoluciones administrativas de carácter individual favorables a un particular sólo podrán ser modificadas por el Tribunal Federal de Justicia Fiscal y Administrativa mediante juicio iniciado por las autoridades fiscales.

Cuando la Secretaría de Hacienda y Crédito Público modifique las resoluciones administrativas de carácter general, estas modificaciones no comprenderán los efectos producidos con anterioridad a la nueva resolución.

Las autoridades fiscales podrán, discrecionalmente, revisar las resoluciones administrativas de carácter individual no favorables a un particular emitidas por sus subordinados jerárquicamente $y$, en el supuesto de que se demuestre fehacientemente que las mismas se hubieran emitido en contravención a las disposiciones fiscales, podrán, por una sola vez, modificarlas o revocarlas en beneficio del contribuyente, siempre y cuando los contribuyentes no hubieren interpuesto medios de defensa y hubieren transcurrido los plazos para presentarlos, y sin que haya prescrito el crédito fiscal.

Lo señalado en el párrafo anterior, no constituirá instancia y las resoluciones que dicte la Secretaría de Hacienda y Crédito Público al respecto no podrán ser impugnadas por los contribuyentes.

No debe esperarse a que el superior jerárquico revise discrecionalmente las resoluciones fiscales adversas a un contribuyente para ser modificadas o revocadas en beneficio de éste. Lo menos que puede suceder es una modificación para no incurrir en responsabilidad el Servicio de Administración Tributaria al no obedecer una Jurisprudencia del Poder Judicial y tener que pagar una indemnización por daños y perjuicios. (Art. $6^{\circ}$ de la Ley Federal de Procedimiento Contencioso Administrativo) 
Pero no impide que los Contribuyentes impulsen esta Reconsideración Administrativa a través de un escrito que no solamente tiene los requisitos del Artículo 18 y 19 del Código Fiscal de la Federación y expresando los Agravios.

Tan útil es que detiene el Procedimiento Administrativo de Ejecución hasta que se resuelva el mismo y por ello es muy práctica su utilización en aquellos casos que parecen no tener solución con una Defensa Legal ordinaria.

"RECONSIDERACIÓN ADMINISTRATIVA PREVISTA POR EL ARTÍCULO 36 DEL CÓDIGO FISCAL DE LA FEDERACIÓN. IMPIDE EJECUCIÓN.- La determinación de un crédito alcanza firmeza cuando el contribuyente no la haya impugnado o porque habiéndolo hecho, se haya confirmado la resolución del fisco y entonces puede ser legalmente exigido mediante el procedimiento administrativo de ejecución a que se refiere el artículo 145 del Código Fiscal de la Federación. Esto es, la seguridad jurídica postulada por nuestra Constitución exige que para poner en marcha el procedimiento administrativo de ejecución debe existir un crédito exigible, teniendo este carácter el que no puede variar por haber sido consentido o porque las autoridades han determinado su legalidad una vez puesta a su consideración. Ahora bien, el artículo 36 , en sus tercero y cuarto párrafos sustancialmente prevé que las autoridades fiscales podrán, discrecionalmente, revisar las resoluciones administrativas de carácter individual no favorables a un particular emitidas por su subordinado jerárquicamente y podrán, por una sola vez modificarlas o revocarlas en beneficio del contribuyente, por lo que si existe la solicitud de revisión administrativa, aunque ésta no constituye un medio de impugnación en estricto sentido, sí representa un derecho constituido a favor del gobernado y, por ello, impide la ejecución de la resolución puesta a consideración mientras no se resuelva, esto es, en tanto tenga la expectativa de que la resolución en su contra se revoque o modifique, no es dado a la autoridad continuar con el procedimiento coactivo respecto de la garantía que exige un crédito firme."

Novena Época, Instancia: Tribunales Colegiados de Circuito, Fuente: Semanario Judicial de la Federación y su Gaceta XVII, Junio de 2003, Página: 1057, Tesis: I.9o.A.70 A, Tesis Aislada, Materia(s): Administrativa. Registro No 184031 
La Administración Local Jurídica no puede resolver sin fundamentos ni motivos jurídicos, ni excusarse de que no se trata de una instancia legal por tratarse de una facultad discrecional interna y como ya quedó firme el crédito fiscal éste ya no es impugnable por esta vía ni por ninguna otra.

Esto es lo que se puede esperar como respuesta de la autoridad fiscal, sin embargo, el Poder Judicial de la Federación ha resuelto que toda resolución fiscal emitida por medio de la reconsideración administrativa debe cumplir con los requisitos del Artículo 16 Constitucional y además sí afecta el interés jurídico del promoverte.

\section{"RECONSIDERACIÓN ADMINISTRATIVA PREVISTA EN EL ARTÍCULO 36 DEL CÓDIGO FISCAL DE LA FEDERACIÓN. LA RESOLUCIÓN QUE EN ELLA SE EMITE SE ENCUENTRA SUJETA A LOS REQUISITOS DEL ARTíCULO 16 CONSTITUCIONAL. Si bien es cierto que la reconsideración administrativa que prevé el artículo 36, tercer párrafo, del Código Fiscal de la Federación, se instituyó como un mecanismo excepcional de la legalidad de los actos administrativos en materia fiscal, cuyo ejercicio pueden desarrollar discrecionalmente las autoridades administrativas, y que la resolución que se dicta en ella es en ejercicio de las facultades discrecionales concedidas por la ley a las autoridades correspondientes, también lo es que ello no exime de que tales decisiones estén sujetas a los requisitos de fundamentación, motivación, congruencia y exhaustividad exigidos por el artículo 16 de la Constitución Política de los Estados Unidos Mexicanos, lo cual permite que los actos discrecionales sean controlados por la autoridad jurisdiccional, a través del juicio de garantías." Novena Época, Instancia: Tribunales Colegiados de Circuito, Fuente: Semanario Judicial de la Federación y su Gaceta XXII, Noviembre de 2005 Página: 922, Tesis: VI.3o.A.255 A, Tesis Aislada, Materia(s): Administrativa. Registro No 176652}

Resulta relevante la siguiente Tesis que ha establecido cuando son impugnables las Resoluciones de una Reconsideración Administrativa:

\footnotetext{
"RECONSIDERACIÓN ADMINISTRATIVA. LAS RESOLUCIONES DICTADAS EN ELLA, SÓLO SON INIMPUGNABLES CUANDO FAVORECEN AL PARTICULAR.- Una recta interpretación de lo previsto en el artículo 36 del Código Fiscal de la Federación permite
} 
establecer que las resoluciones pronunciadas en la reconsideración administrativa son inimpugnables, única y exclusivamente cuando a través de las mismas las autoridades fiscales, en uso de facultades discrecionales, modifican o revocan en beneficio del contribuyente una resolución administrativa que le hubiere sido adversa, lo que se estima de obvia comprensión, puesto que no sería jurídico que se inconformara con una resolución favorable a su interés, emitida sin petición o gestión alguna de su parte. En cambio, si el particular instó la reconsideración como un medio de obtener la revocación o modificación de una resolución administrativa, y la autoridad fiscal declara improcedente sus pretensiones, entonces la legalidad de la resolución relativa puede cuestionarse mediante la promoción del juicio de nulidad, habida cuenta que el precepto de mérito solamente establece dicha falta de impugnación respecto de resoluciones pronunciadas en beneficio de los contribuyentes, pero no en su perjuicio."Novena Época, Instancia: Tribunales Colegiados de Circuito, Fuente: Semanario Judicial de la Federación y su Gaceta XVI, Septiembre de 2002Página: 1432, Tesis: XVII.3o.10 A, Tesis Aislada, Materia(s): Administrativa. Registro $N^{\circ} 185919$.

Debe tenerse cuidado en el medio de defensa que se elija una vez resuelta la reconsideración administrativa, pues hay distintos criterios que indican al Juicio de Amparo ante el Juzgado de Distrito como la vía correcta.

"RECONSIDERACIÓN ADMINISTRATIVA PREVISTA EN EL ARTÍCULO 36, TERCERO Y CUARTO PÁRRAFOS, DEL CÓDIGO FISCAL DE LA FEDERACIÓN, VIGENTE A PARTIR DEL 10. DE ENERO DE 1996. EN CONTRA DE LA RESOLUCIÓN QUE LE RECAE PROCEDE EL AMPARO INDIRECTO, INDEPENDIENTEMENTE DEL RESULTADO EN CUANTO AL FONDO.- La Segunda Sala de la Suprema Corte de Justicia de la Nación ha sostenido que el ejercicio de las facultades conferidas a las autoridades hacendarias para revisar y, en su caso, modificar o revocar por una única vez las resoluciones administrativas que emitan sus inferiores jerárquicos que sean desfavorables a los intereses de los particulares, que se prevé en el artículo 36, tercero y cuarto párrafos, del Código Fiscal de la Federación vigente a partir del 10. de enero de 1996, no constituye un recurso ni una instancia jurisdiccional a través del cual puedan combatirse tales determinaciones, en la medida en que la reconsideración 
administrativa se instituyó como un mecanismo excepcional de autocontrol de la legalidad de los actos administrativos en materia fiscal, que tiene como fin otorgar un trato justo a los contribuyentes que notoriamente les asista la razón y que hubieran perdido toda posibilidad de controvertirlos, siempre que el crédito no haya prescrito, lo que justifica el que estas resoluciones no puedan ser controvertidas a través de algún medio ordinario de defensa. Ahora bien, la resolución que recaiga a dicha reconsideración está sujeta a los requisitos de fundamentación, motivación, congruencia y exhaustividad exigidos por la Constitución Política de los Estados Unidos Mexicanos, por lo que su incumplimiento puede combatirse en amparo indirecto en términos de la fracción II del artículo 114 de la Ley de la materia, si se estima que aquélla es violatoria de garantías. Lo anterior porque el juicio de amparo no es un medio de defensa ordinario, sino un medio de control constitucional que conforme a su naturaleza tiene el carácter de extraordinario, como se desprende de los artículos 103 y 107 constitucionales que lo regulan, por lo que procede únicamente respecto de aquellos actos contra los cuales la ley secundaria no concede recurso alguno, por virtud del cual puedan repararse los perjuicios que dichos actos ocasionan al particular."

Contradicción de tesis 36/2006-SS. Entre las sustentadas por el Tercer Tribunal Colegiado en Materia Administrativa del Sexto Circuito y el Tribunal Colegiado del Décimo Noveno Circuito. 7 de abril de 2006. Cinco votos. Ponente: Margarita Beatriz Luna Ramos. Secretaria: Ma. de la Luz Pineda Pineda.

Tesis de jurisprudencia 61/2006. Aprobada por la Segunda Sala de este Alto Tribunal, en sesión privada del diecinueve de abril de dos mil seis. Novena Época, Instancia: Segunda Sala, Fuente: Semanario Judicial de la Federación y su Gaceta XXIII, Mayo de 2006 Página: 325, Tesis: 2a./J. 61/2006 Jurisprudencia, Materia(s): Administrativa. Registro No 175015

Como se aprecia en el texto anteriormente transcrito, sí la autoridad fiscal no obedece una Jurisprudencia del Poder Judicial de la Federación y determina un crédito fiscal con base a una ley declarada inconstitucional, y aún quedando firme ese crédito fiscal, es fácilmente impugnable y con muchas posibilidades de obtener una fallo favorable, ya que se trata de una clara 
inobservancia a un órgano de control constitucional y se emitió una resolución en contra de las disposiciones que deben aplicarse como lo son el Artículo $6^{\circ}$ de la Ley Federal del Procedimiento Contencioso Administrativo y 34 del Reglamento Interior del Servicio de Administración Tributaria.

Por otra parte, el desechamiento o la resolución de esta reconsideración no son impugnables a través del Tribunal Federal de Justicia Fiscal y Administrativa, sino que tiene que acudirse directamente al Juzgado de Distrito con una demanda de amparo indirecto.

"RECONSIDERACIÓN.- LA RESOLUCIÓN DICTADA EN EL RECURSO PREVISTO EN EL ARTÍCULO 39 DE LA LEY FEDERAL DE COMPETENCIA ECONÓMICA, NO ES IMPUGNABLE ANTE EL TRIBUNAL FEDERAL DE JUSTICIA FISCAL Y ADMINISTRATIVA.- El citado artículo otorga a los afectados por las resoluciones dictadas por la Comisión Federal de Competencia la facultad de impugnarlas ante la propia Comisión, a través del recurso de reconsideración; asimismo, dispone el plazo para la interposición de éste, las formalidades de su tramitación, el otorgamiento de la suspensión y el propósito de dicho medio de defensa (revocar, modificar o confirmar la resolución reclamada). Como se observa, el recurso de reconsideración es, en sí, un medio ordinario de defensa, previsto en ley, que procede en contra de las determinaciones de la Comisión Federal de Competencia, dictadas con apoyo en la ley de la materia. Por otro lado, el artículo 2 de la Ley Federal de Procedimiento Contencioso Administrativo prevé que el juicio contencioso administrativo federal procede, entre otros actos, en contra de las resoluciones administrativas definitivas que establece la Ley Orgánica del Tribunal Federal de Justicia Fiscal y Administrativa. Ahora bien, ni en la fracción XV del artículo 11 de la citada Ley Orgánica vigente hasta el 6 de diciembre de 2007, ni en la fracción XV de su correlativo artículo 14 de la vigente, se establece expresamente dentro de la competencia del Tribunal Federal de Justicia Fiscal y Administrativa, la resolución dictada en el recurso de reconsideración previsto en el artículo 39 de la Ley Federal de Competencia Económica. De lo anterior se concluye, que la resolución dictada dentro del recurso no es impugnable a través de medio ordinario de defensa alguno, por lo que sólo puede combatirse a través del juicio de amparo indirecto, en términos del numeral 107, fracción IV, de la Constitución Política de los Estados Unidos 
Mexicanos."[J]; 9a. Época; 2a. Sala; S.J.F. y su Gaceta; Tomo XXVII, Marzo de 2008; Pág. 174. Registro IUS No 170034.

"RECONSIDERACIÓN ADMINISTRATIVA. SU
DESECHAMIENTO NO ES IMPUGNABLE A TRAVÉS DEL
JUICIO DE NULIDAD ANTE EL TRIBUNAL FEDERAL DE
JUSTICIA FISCAL Y ADMINISTRATIVA.- De conformidad con los párrafos tercero y cuarto del artículo 36 del Código Fiscal de la Federación, el ejercicio de las facultades conferidas a las autoridades hacendarias para revisar y, en su caso, modificar o revocar, por una sola vez, las resoluciones administrativas emitidas por sus inferiores jerárquicos que sean desfavorables a los intereses de los particulares, no constituye un recurso o medio de defensa con que éstos cuenten para impugnar tales determinaciones, lo cual encuentra su justificación en el hecho de que la reconsideración administrativa se instituyó como un mecanismo excepcional de autocontrol de la legalidad de los actos administrativos en materia fiscal, que tiene por objeto otorgar un trato más justo a los contribuyentes a los que notoriamente les asista la razón y que no pueden acudir a medio ordinario de defensa alguno por haber perdido su derecho a hacerlo, siempre que el crédito fiscal no haya prescrito. Por tanto, el desechamiento de una solicitud de reconsideración administrativa no es impugnable ante el Tribunal Federal de Justicia Fiscal y Administrativa a través del juicio de nulidad, ya que el artículo 202, fracción XIV, del citado código tributario, establece expresamente que el referido juicio no procede en los casos en que la improcedencia resulte de alguna disposición de dicho ordenamiento legal."

Contradicción de tesis 61/2004-SS. Entre las sustentadas por los Tribunales Colegiados Segundo en Materia Administrativa del Tercer Circuito y Segundo en Materias Penal y Administrativa del Décimo Séptimo Circuito. 25 de junio de 2004. Unanimidad de cuatro votos. Ausente: Guillermo I. Ortiz Mayagoitia. Ponente: Guillermo I. Ortiz Mayagoitia; en su ausencia hizo suyo el asunto Margarita Beatriz Luna Ramos. Secretaria: Georgina Laso de la Vega Romero.

Tesis de jurisprudencia 97/2004. Aprobada por la Segunda Sala de este Alto Tribunal, en sesión privada del nueve de septiembre de dos mil cinco.Novena Época, Instancia: Segunda Sala, Fuente: Semanario Judicial de la Federación y su Gaceta XXII, Noviembre de 2005, Página: 52, Tesis: 2a./J. 97/2004, Jurisprudencia, Materia(s): Administrativa Registro № 176651 
"RECONSIDERACIÓN ADMINISTRATIVA PREVISTA EN EL ARTÍCULO 36 DEL CÓDIGO FISCAL DE LA FEDERACIÓN. LA RESOLUCIÓN QUE EN ELLA SE EMITE PUEDE IMPUGNARSE MEDIANTE EL JUICIO DE AMPARO.- La resolución contra la cual se pide la reconsideración, no es atacable por los medios ordinarios, en términos del artículo 36 del Código Fiscal de la Federación, que establece que las autoridades podrán revisar las resoluciones administrativas de carácter individual no favorables al particular, en el supuesto de que se demuestre fehacientemente que se emitieron en contravención a las disposiciones fiscales, siempre y cuando no se hubieren interpuesto medios de defensa y hayan transcurrido los plazos para presentarlos, resolución que no constituirá instancia y, por tanto, los contribuyentes no estarán en aptitud legal de impugnarla; sin embargo, la resolución que recaiga a dicha reconsideración podrá ser combatida a través del juicio de amparo, cuenta habida que éste no es un recurso o medio de defensa ordinario, sino que es un remedio constitucional extraordinario, conforme a su esencia y naturaleza, que sólo procede contra actos respecto de los cuales la ley no concede alguno por virtud del cual puedan repararse, en la vía común, los perjuicios que dichos actos causen, pues de estimar lo contrario, el amparo se entenderá como un recurso más, con notoria violación del espíritu jurídico que informó su creación, pues no se tuvo ese propósito, sino el de crear una institución de carácter extraordinario para el mantenimiento del orden constitucional; y si bien el citado artículo 36 impide la impugnación de la determinación pronunciada en la reconsideración administrativa, ello no puede ser regulador del juicio de garantías, toda vez que el juicio de amparo, está previsto en los artículos 103 y 107 de la Constitución Política de los Estados Unidos Mexicanos y en su ley reglamentaria.

Novena Época, Instancia: Tribunales Colegiados de Circuito, Fuente: Semanario Judicial de la Federación y su Gaceta XXII, Noviembre de 2005, Página: 921, Tesis: VI.3o.A.254 A, Tesis Aislada, Materia(s): Administrativa. Registro No 176653.

\section{Conclusiones:}


a).- La reconsideración administrativa es muy útil y práctica para los contribuyentes o contadores públicos en los casos de créditos fiscales que ya sea extemporáneo utilizar un medio de defensa.

b).- No se tiene nada que perder y mucho que ganar al estar consciente el contribuyente de que sus posibilidades de restablecer o resucitar una resolución son muchas y no requieren de garantía del interés fiscal ni se tienen exigencias de expresión en términos jurídicos ad hoc en ese escrito y además, se detiene el procedimiento administrativo de ejecución.

c).- Pueden argumentarse tanto agravios de derecho como de hechos así como la imposible reparación de los daños que pueda causar la ejecución de la resolución.

d).- En caso de que no se obedezca una Jurisprudencia de la Suprema Corte de Justicia de la Nación se debe solicitar además el pago de una indemnización por daños y perjuicios.

e).- Las autoridades fiscales nunca serán ni tendrán la última decisión en cualquier petición o solicitud que se le formule pues se atentaría contra el derecho de audiencia de los contribuyentes, por lo que las frases "sus resoluciones no serán impugnables" no tienen efecto alguno.

\section{BIBLIOGRAFIA -- WEBGRAFÍA}

MARGÁIN, MANAUTOU Emilio, El Recurso Administrativo, 8va ed. México, Editorial Porrúa, S.A., 2010.

MARGÁIN, MANAUTOU Emilio, De lo Contencioso Administrativo, décimo tercera ed. México, Editorial Porrúa, S.A., 2010.

http://www2.scjn.gob.mx/red2/2sjt/[consultada el 2 de febrero de 2013]

\section{LEGISLACIÓN CONSULTADA}

Constitución Política de los Estados Unidos Mexicanos

Código Fiscal de la Federación

Ley Federal de los Derechos del Contribuyente. 